\title{
International Teledermatology Review
}

\author{
Karen $_{\text {McKoy }}{ }^{1}$ (D) Saul Halpern ${ }^{2} \cdot$ Kudakwashe Mutyambizi $^{3}$ \\ Accepted: 19 May 2021 / Published online: 28 July 2021 \\ (C) The Author(s), under exclusive licence to Springer Science+Business Media, LLC, part of Springer Nature 2021
}

\begin{abstract}
Purpose of Review The use of teledermatology has been evolving slowly for the delivery of health care to remote and underserved populations. Improving technology and the recent COVID-19 pandemic have hastened its use internationally.

Recent Findings Some barriers to the use of teledermatology have fallen considerably in the last year.

Summary Teledermatology use has increased significantly in recent years in both government-sponsored and private health care systems and individual practices. There are no recognized international practice guidelines and variable use within countries. Many barriers remain to increasing the use of teledermatology.
\end{abstract}

Keywords International teledermatology $\cdot$ COVID dermatology $\cdot$ COVID teledermatology $\cdot$ COVID telemedicine $\cdot$ International telemedicine

\section{Introduction}

In 2009, the eHealth survey of the World Health Organization (WHO) showed that a teledermatology service was established in $16 \%$ of the 114 responding countries [1]. This survey was repeated in 2015 with a response from 125 countries, showing a teledermatology service of some type, from pilot to established, in $46 \%$ of the responding countries [2].

Teledermatology (TD), involving consultation and management of patients with skin problems by remote health care providers, is increasingly recognized as an important component of health care delivery. The last reviews of international TD were in 2010 [3] and 2015 [4].

TD practice has evolved since then because of improvement in technology, especially in mobile devices [5], and particularly because of the current COVID-19 pandemic [6].

This article is part of the Topical Collection on Teledermatology

Karen McKoy

thrlmcky@gmail.com

1 Lahey Clinic Department of Dermatology, Harvard Medical School, Burlington, MA, USA

2 Department of Dermatology, East Kent Hospitals University NHS Trust, Kent, UK

3 Department of Dermatology, University of Texas McGovern Medical School, MD Anderson Cancer Center, Houston, TX, USA
This updated review builds upon those previous articles as well as updating the literature in the last 5 years. In addition, a survey was constructed in an attempt to get a picture apart from the literature on the practice of TD internationally, outside of the USA (in which a review was done recently) [7•].

Consultations in TD can be done asynchronously (store and forward) with digital images or synchronously (video real time) or a hybrid of the two methods to any location with Internet service or mobile phone service with an adequate bandwidth. The consultations can be direct to patients or provider to provider.

TD offers many advantages over in-person health care, including reductions in wait time for care, improved workflow efficiency, possible health care cost savings, and provision of care to underserved regions and populations. It can also be used as a triage tool to identify urgent and severe health problems and as a follow-up tool for established patients to save time and travel costs.

In terms of outcomes, the evidence to date supports both diagnostic and treatment accuracy and cost effectiveness of TD $[8,9]$. Accessibility to health care and efficiency of practice in terms of "no shows" and appointment cancelations are improved with TD [10-12]. And TD has had a beneficial impact in improving dermatological access to rural areas. Other outcome studies confirm the usefulness of TD for geriatric patients, who often have trouble getting to appointments; TD helped to treat $67 \%$ of the dermatoses of older individuals in a large Brazilian study [13]. In addition, in-house 
dermatology consultation services for hospitalized patients can be instituted in a timely fashion to reliably and effectively bridge access gaps, improve diagnostic accuracy, and differentiate therapeutic approaches while maintaining patient satisfaction [14-16]. Follow-up for chronic disease with directaccess online care had an equivalent quality of life outcomes as those seen in person with the same or higher efficacy as well as reducing transportation and health care costs [17-21]. Certain conditions (acne, psoriasis, eczema, rashes, rosacea, and lesions of concern) were particularly amenable to TD, whereas other visit types (total body skin examinations) were not reliably accomplished through this modality [22]. Patients and physician users are generally satisfied with the use of TD, although most still prefer face to face [23-26].

Government initiatives to decrease health care costs and to increase specialty health care are one of the major factors for the adoption of telemedicine services. Such government initiatives can be found in Canada, the UK, and Saudi Arabia. For instance, Canada announced the investment of US\$500 million to bring high-speed internet in 300 rural and remote communities by 2021 [27].

\section{COVID-19 Pandemic Impact on TD Use}

There has been a profound effect of the pandemic on dermatology practice due to social distancing measures and to concerns that examinations may be a vector of COVID-19 transmission.

The pandemic has substantially contributed to the increased use of TD, as it has limited traditional consultation and health care access. TD has come to the rescue in this situation by extending consultation for nonessential conditions to patient's homes. In many countries, teleconsultation platforms were launched after streamlining regulations to meet the demand and needs for patient care. However, elderly patients and those with language differences may be experiencing unequal access to remote care during the pandemic due to limited proficiency with technology, the administrative burden to mobilize an interpreter service, and the hesitancy of patients to receive medical care via virtual platforms.

A global survey of over 700 dermatologists showed a 3fold increase in the number of dermatologists practicing TD during the pandemic compared to before, with North American responders indicating the highest use. There was a $53 \%$ reduction in the number of dermatologists in all practice settings providing face-to-face consultations and a $49.1 \%$ increase in TD consultations; $15.6 \%$ of dermatologists stopped delivering care during this pandemic. WhatsApp was the most common platform across all continents (Europe, $62.4 \%$; Asia 62.6\%; North America 39.4\%; Central/South America, $36.7 \%)[28 \bullet \bullet]$.
European dermatologists shifted en masse to TD during the first wave of the COVID-19 pandemic, and most of them disliked the videoconferencing experience [29].

During this time of rapid change, dermatologists must simultaneously aim to protect and remain available to patients while preserving their own safety. The expansion of telehealth by payers acknowledges these needs. While challenges exist with TD, the pandemic has created the opportunity to explore and refine this technology, offering an opportunity to continually deliver care during the pandemic [30-36].

Asian telehealth platforms are reporting drastically increased usages, such as the Indonesian telehealth platforms Alodokter, Halodoc, and GrabHealth, driven by government support and recommendation. The Doctor Anywhere COVID-19 Medical Advisory Clinic has also been rolled out across several Asian countries such as Singapore, Thailand, and Vietnam, in which patients can undergo a video consultation through the app if they suspect they might have COVID-19 [38].

\section{Methods}

A survey instrument was formatted in Google forms in English and distributed electronically to international personal contacts of the authors, to 85 international dermatology and teledermatology societies who are members of the International League of Dermatological Societies, and to members of the International Society of Teledermatology. Answers from US dermatologists were excluded. Participants accessed the survey via a provided link. This was an optionally anonymous survey. A Chinese version was sent directly to Chinese contacts as the Google platform is not permitted in China.

Survey questions asked about types of country-specific health care systems, devices used for remote consults, practice settings, method(s) of consultation (store-forward and/or live video), whether the consult was direct to the patient or to another health care provider, countries served, whether teledermoscopy and telepathology were done, estimated number of annual consults, providing unpaid volunteer service, methods of reimbursement, and the impact of COVID on teledermatology practice.

A literature review was done for 2015-2021 in PubMed with search terms international AND teledermatology and global AND teledermatology and with the name of individual countries contacted for the survey AND teledermatology. A search was also done with the terms COVID AND teledermatology and COVID AND dermatology.

In addition to the survey, authors personally communicated with international colleagues; their comments outside of the survey are referenced in the text. 


\section{Survey Results (see Table 1)}

One hundred twenty-two responses were received. Ten responses were excluded for the following reasons: No country was noted in 3 responses, one reply was from a commercial entity (which offered direct to patient consults for pigmented lesions), one entry was entered in duplicate, and 2 responses were from the USA. The majority of respondents experienced an increase in TD numbers during the pandemic, although some who perform store-forward consults to providers had decreased numbers as patients did not come into clinics. Responses are tabulated in Table 1.

\section{World Regions}

Most TD programs are active in North and South America and Europe [37].

Table 1 Survey responses

\begin{tabular}{|c|c|}
\hline $\begin{array}{l}\text { Regional responses (of } 33 \\
\text { countries represented) }\end{array}$ & $\begin{array}{l}\text { Caribbean }-1 \\
\text { Central and South America }-29 \\
\text { Canada }-2 \\
\text { Western Europe }-12 \\
\text { Eastern Europe }-7 \\
\text { Africa }-4 \\
\text { Middle East }-10 \\
\text { Indian subcontinent }-10 \\
\text { Far East }-32 \\
\text { Pacific region }-4\end{array}$ \\
\hline $\begin{array}{l}\text { Practice types (many } \\
\text { respondents had } \\
\text { multiple practice roles) }\end{array}$ & $\begin{array}{l}\text { Academic }-58 \% \\
\text { Group practice }-39 \% \\
\text { Private practice }-73 \% \\
\text { Commercial employment }-9 \%\end{array}$ \\
\hline $\begin{array}{l}\text { Reimbursement sources } \\
\text { (note many } \\
\text { had multiple sources) }\end{array}$ & $\begin{array}{l}\text { National health care system }-59 \% \\
\text { Private insurance }-85 \% \\
\text { Self-pay }-73 \% \\
\text { Unpaid volunteer work }-36 \%\end{array}$ \\
\hline TD methods used & $\begin{array}{l}\text { Video synchronous }-55 \% \\
\text { Store-forward asynchronous - } 48 \% \\
\text { Hybrid store-forward video }-43 \%\end{array}$ \\
\hline Devices used & $\begin{array}{l}\text { Telephone }-33 \% \\
\text { Mobile devices - 79\% } \\
\text { Desktop computer - 76\% } \\
\text { Unencrypted email }-31 \%\end{array}$ \\
\hline Consult source & $\begin{array}{l}\text { Other health care providers }-57 \% \\
\text { Direct to patient }-89 \% \\
\text { Consultation to patients or providers in } \\
\text { other countries }-14 \%\end{array}$ \\
\hline Teledermoscopy provided & $15 \%$ of responses \\
\hline $\begin{array}{l}\text { Teledermatopathology } \\
\text { provided }\end{array}$ & $9 \%$ of responses \\
\hline $\begin{array}{l}\text { Number of referral sites } \\
\text { served }\end{array}$ & From none to 300 (10 mean $/ 4$ median $)$ \\
\hline $\begin{array}{l}\text { Number of annual consults } \\
\text { per respondent }\end{array}$ & $\begin{array}{l}\text { From none to } 27,926 \text { (984 mean/110 } \\
\text { median) }\end{array}$ \\
\hline
\end{tabular}

\section{Canada}

Policy surrounding telemedicine differs according to provinces. Government support of telehealth initiatives promises continued development [40]. TD is available, with some restrictions, in 6 of the 10 provinces (British Columbia, Alberta, Manitoba, Ontario, Quebec, and Nova Scotia) [41]. Shared Care is a provincial "not for profit" program in which dermatologists are reimbursed for their participation in the project on a per consult basis; it is being used in Alberta, British Columbia, Northwest Territories, and Prince Edward Island [42]. TD is also a service of the Ontario eConsult Program, available at no cost as part of Ontario's publicly funded health care system [43].

A recent task force found that half of primary care providers and specialists offer no interactive electronic services to patients [44]. In this gap, virtual private care has developed. There are several Canadian-based websites which offer health services directly to paying patients. During the pandemic, virtual care went from being extremely rare to "the default." After the start of COVID, according to a Canada Health Infoway survey, more than half of Canadians in spring 2020 said their most recent health encounters in 2020 were virtual [45].

\section{English Speaking Caribbean}

Some in Trinidad and Tobago provide TD using WebEx or a hybrid model (Dr. Jeffrey Edwards, personal communication, February 2021). Another practitioner uses photographs, telephone, and video consultation in Antigua, Montserrat, St Kitts and Nevis, and the UK (Dr. Ronnie Cooper, personal communication, February 2021).

\section{Central and South America}

A total of 29 survey responses were from 9 countries in this area. Brazilian dermatologists are the busiest with 5 dermatologists reporting a total of over 29,000 annual consults, primarily to other providers. Chile was next in numbers at 2000 annual consults, again to other providers. Eight Argentinian dermatologists reported almost 2500 total consults, both to providers and patients. All other countries reported low numbers of consults.

With limited education, economic constraints, poor broadband service, and political issues affecting health care, TD is not widely practiced and few commercial platforms are available. Many institutions have tried TD, but most stopped within a few years. WhatsApp and Zoom allowed an increase in TD during the pandemic for some in private practice [46]. The 2015 WHO eHealth survey noted TD practice of some type in 6 out of 12 South American countries [47•]. 
Brazil has the most developed TD practice in Latin America. Large-scale public TD programs have been developed in much of the country and some work with artificial intelligence (AI) incorporated [48, 49].

In 2018 in São Paulo, Brazil, 57,832 patients had been waiting for an appointment with a dermatologist through the public health system for almost a year. City Hall decided to create a program in conjunction with Hospital Israelita Albert Einstein, a private hospital, to assist using TD; 30,916 patients participated in the project, with 55,012 lesions photographed, resulting in nearly 165,000 images evaluated by 13 dermatologists over 12 months [50]. The same authors showed teletriage of pediatric patients addressed $63 \%$ of the lesions without the need for an in-presence visit [51].

In another state, the Telehealth Network of the state Minas Gerais is a public telehealth service supporting primary care practitioners in 660 of the 853 municipalities in the state in the southeast of Brazil. The most frequently requested specialty is dermatology [52].

In Chile, with a national telehealth program, TD consults composed over a quarter of consults with 37,424 TD consults from 2014 to 2016 [53].

In 2001, the French public health service launched a successful project delivering TD to remote health centers in French Guiana to tackle health care access inequalities [54].

Other countries are still slow on the uptake of telemedicine [55].

\section{Europe}

Nineteen survey responses came from this region. Seven were from Eastern Europe, indicating the use of TD.

Relative uptake and enthusiasm for TD in Europe appear to be related to national health care systems and ratios of dermatologists to the population. Countries such as Spain, the Netherlands, and the UK, which have among the lowest number of dermatologists per million inhabitants and whose dermatologists are mostly based in the public sector rather than in private practice, have far greater experience of TD and have significant mature mass digital services [56-58].

In the UK, national surveys revealed an increase in active participation in TD from $17 \%$ in 2006 to $48 \%$ in 2016, and dermatologists with any experience of TD rose from 27 to $82 \%$ over the same period [57]. The UK National Health Service (NHS) from 2018 has mandated digital referrals to secondary care with an "advice and guidance" facility that allows the attachment of digital images for virtual triage. Many localities have developed their own strategies utilizing adapted public sector IT systems or private provider platforms to manage primary care outpatient and, in some cases, secondary care inpatient demand.

In the Netherlands, one major telemedicine provider, KSYOS, established in 2005, links almost 5000 GPs with
285 Dutch dermatologists, with an average of 300 teleconsultations per week. Telecare is approved and embedded in the health care establishment [60].

Several areas in Spain have well-established TD services; the skin cancer screening program for Andalucia managed 8000 digital cases in 2018, with additional TD used for inflammatory skin disease, including monitoring of psoriasis patients using a mobile app (D. Moreno-Ramirez, personal communication, Oct 2020 \& World Congress of Dermatology, Milan, June 15, 2019).

In many other Western European countries, there have been local or regional TD services both for primary and secondary care support [61-65]. Publications show its use in geographically challenged and niche areas such as to the Faroe Islands from Denmark [66], specialist opinion for prisons in France [67], and to emergency care departments in Germany [68]. There is also evidence of experimentation and usage of mobile-based TD in several countries $[69,70]$ including monitoring and management of patients with chronic inflammatory conditions such as psoriasis [71].

There appears to be a paucity of published evidence of TD usage from Eastern European countries although no doubt there has been a degree of uptake for the same reasons as elsewhere [72]. In Russia, with a state-run health care insurance which is without charge, Alexey Sergeev, Professor, Sechenov University, Moscow Russia, states that "thousands of us consult online for free and for reward" through TD. In addition, there are "fully networking Russian-made dermatoscopes that offer cloud diagnosis and automatic cancer recognition for free instantly - inside a social network of all dermatologists in Russia" (A. Sergeev MD, personal communication, October 2020).

\section{Middle East and North Africa}

Ten survey responses came from this region. TD has come to the rescue in this situation by extending consultation for nonessential conditions to patient's homes, most from Iran, which indicated active informal TD use.

Less than half of respondents in this region to a WHO 2015 survey have any type of TD program. Jordan and Ethiopia were the only countries with an established program [73].

In Turkey, a recent study surveyed 107 dermatologists regarding informal teledermatology use before and after the COVID-19 pandemic began.

Before the pandemic, $40 \%$ of responding dermatologists used live video consults with patients, and $85 \%$ used storeforward via mobile device or email; $95 \%$ used WhatsApp as a platform. During the pandemic, $63 \%$ used video, and $72 \%$ used store-forward methods to consult with patients; $57.9 \%$ of participating dermatologists stated that they had a moderate level of knowledge about teledermatology, and $64.4 \%$ wanted teledermatology methods to be established officially [74]. 
The use of TD in Egypt is uncommon outside of large academic centers for remote consults to distant rural areas [75]. Teledermatopathology and teledermoscopy are not practiced (Pakinam Nabil Ibrahim MD, personal communication, December 2021).

\section{Sub-Saharan Africa}

A contemporary informal survey estimates $<1$ dermatologist per million population across the continent. In this area, mHealth, which relies on mobile phones and wireless networks, is preferred, being portable, accessible, and cheaper than broadband. The African Union and World Bank have set the goal of increasing internet connectivity from the current $22 \%$ to every person on the continent by 2030 [76], which would provide infrastructure support for the expansion of teledermatology. Teledermali is a program in Mali, supporting 67 community health centers. A 2year pilot conducted in Mali from 2015 to 2017, using the system Bogou, showed a vast improvement in the dermatologic knowledge of health care workers who triaged cases to consulting teledermatologists and improvement in the management of dermatologic conditions [77]. Similar programs are being built in Togo and Mauritania [78].

In South Africa, a 2016 critique of teledermatology indicated that 4 of 8 original programs remained active at that time [79••].

The teaching hospitals in the Western Cape Province provide TD through an online application VULA, which allows provider-to-provider referrals to dermatology using store and forward teledermatology. Referrals are addressed in real time, with treatment and triage decisions concluded while the patient waits with the referring provider. In addition to providing needed services, the teledermatology application has been a robust dermatology teaching tool. A direct-to-patient privatesector program, Dr. Derma, was launched in March 2020 in response to the COVID-19 pandemic, providing approximately 2000 consultations to date, and is available across South Africa and some Southern African Development Community countries. This store and forward mobile phone app has the added functionality for providers to send voicemails reinforcing treatment recommendations and for scheduling a video call in complex scenarios. Dr. Derma operates as a virtual practice, where patients have the option to seek further treatment in person from the selected dermatologists (Dr. W. Visser, personal communication, February 2021).

\section{Central Asia (No Survey Responses)}

Central Asian countries could follow the example set by Kazakhstan which is in the adoption stage of telemedicine [80]. Kazakhstan implemented a national telemedicine network in 2004 to eliminate the gap in the availability of specialized medical care for the urban and rural populations. This network combines 199 districts, regions, and organizations. More than 500,000 telehealth consultations have been provided via video conferencing over the last 15 years [81]. Turkmenistan and Uzbekistan have informal local TD [82].

\section{South Asia and Indian Subcontinent (10 Survey Responses from This Region, All of Which Reported an Increase in TD with the Pandemic)}

India India is in the adoption stage of telemedicine, with governance bodies and guidelines in place, indicating the willingness of the government to implement telemedicine programs. However, ongoing issues such as limited infrastructure and lack of comprehensive regulation inhibit this process [83]. One of the major issues in India is the technology illiteracy of the masses and having appropriate devices in spite of having access to high-speed internet. There are several commercially available teleconsultation portals [84].

There is informal TD practiced in Pakistan [85]. Currently, no national telemedicine framework in Bangladesh exists; current systems suffer from a lack of technological infrastructure, health care inequities, and poor treatment quality [86].

Afghanistan and Bangladesh have been reported on a WHO international survey to have TD at a national level [87].

Far East Most of the 31 responses from this region came from the Philippines (16) and Vietnam (13).

Singapore is a front-runner in Asia in terms of telemedicine adoption and health care system efficiency [88] with an intermediate established TD program [89].

China China has varied degrees of implementation across telehealth realms. It demonstrates invention in novel technologies and population health management; however, some telemedicine regulations and implementation are still entry-level and require further clarification [90]. Local pilot TD projects exist. Companies supplying direct-to-patient telehealth subscriptions such as Good Doctor, Alibaba, and Tencent are experiencing growth.

Dr. Yong Cui, chair of the National Telemedicine and Connected Health Center dermatology committee, stated that TD is practiced at the Anhui Province Cloud Hospital in both real-time and asynchronous modes, covering 5 million patients. Development of AI software for TD started in 2018 with the China Skin Imaging Database; 4000 hospitals are projected to be connected to this TD project. To date 300,000 image data sets are included [91].

AIDERMA is the first comprehensive platform for AIassisted diagnosis and treatment of skin patients in China. AIDERMA includes three sections: assisted diagnosis and treatment, continuing education, and consultation. In the assisted diagnosis and treatment, more than 90 kinds of common skin diseases are supported. This purports to be a simple operation 
which provides a diagnosis and treatment ideas [92]. Another application to diagnose psoriasis, eczema, and atopic dermatitis, AIDDA, is available to all doctors in China, and more than 7000 doctors have registered for this application [93].

An overwhelming majority of Chinese dermatologists are favorably disposed to AI and think the role of AI will be in "assisting the daily diagnosis and treatment activities for dermatologists" [94].

Taiwan Only 2 publications on TD have come out of Taiwan. Weekly live-interactive consultation services for dermatology have been done since 2018 [95]. A successful TD pilot was done in Mongolia in 2013 [96].

Korea No information is available in North Korea. South Korea has used live-interactive teledermatology for prisoners [97]. TD using smart phones has been used in the military [98].

Vietnam Vietnam in 2015 had intermediately established the use of TD [99]. In 2018, there were 20 mHealth initiatives in Vietnam. Most of the initiatives were funded by external donors, while the rest were government funded or self-funded. A majority of the initiatives targeted vulnerable and hard-toreach populations, aimed to prevent the occurrence of disease, and used text messaging as part of their intervention. Vietnamese mHealth implementation has been challenged by factors including features unique to the Vietnamese language and sociocultural factors [100]. Thirteen survey responses indicated that the number of consults is generally low.

Malaysia Since COVID, a teledermatology service has been provided from Kuala Lumpur to remote Sabah [101].

Philippines In 2015, WHO reported an intermediate established TD service in the Philippines [102]. With COVID, there are several providers of TD without charge [103]. Currently, the Philippines lacks national legislation, rules, and regulations specific to telemedicine, but during the pandemic, the Department of Health permitted the use of telemedicine [104]. Fee for service TD is offered by many dermatologists.

Sixteen survey results came from this country. The number of annual consults ranged from 30 to 2000, many provided to the military. All reported an increase in consults with the pandemic. One respondent commented that although teleconsultation has existed for the past decade, it is only during the pandemic that its worth has been realized as an important means for accepting consultations from patients.

\section{Oceania}

Survey responses were only from Australia and New Zealand.
Australia Despite the potential of teledermatology to increase access to dermatology services and improve patient care, it is not widely practiced in Australia. In an effort to increase uptake of teledermatology by dermatologists and support best practices, guidelines for teledermatology have been developed by the University of Queensland's Centre for Online Health [105].

Tele-Derm National is provided to registered medical practitioners who are members of the Australian College of Rural and Remote Medicine through its Rural and Remote Medical Education Online (RRMEO) platform. The service has been active since 2003, utilizing a store-and-forward format to provide a specialist dermatologist opinion within $24 \mathrm{~h}[106,107]$.

A survey of Australian dermatologists and dermatology trainees found that mobile teledermatology was common, with more than $50 \%$ saying they sent or received clinical images using a smartphone at least weekly (rising to $89 \%$ of junior practitioners). However, it was also poorly regulated, with limited security measures, documentation of patient consent, or transfer of images to a patient's permanent medical record. Dermatologists reported taking mobile phone images to obtain advice from a colleague, monitor patient progress, communicate with the patient's other doctors, and for educational purposes [108]. Respondents from this country also provided military consult services.

New Zealand According to WHO, New Zealand had a local pilot in 2015 [109]. In order to combat the access gap and prioritize skin cancer diagnosis and treatment, Waikato public dermatologists launched the Suspected Skin Cancer (SSC) service in 2017, a free store-and-forward teledermatology system for Waikato GPs to receive specialist advice within 4 days of referral [110].

Teledermatology applications for consultations using mobile devices for a fee are increasingly prevalent. Other commercial platforms operating (internationally) are DermEngine and MetaOptima [111]. Major health insurers in New Zealand have agreed to fund virtual consultations during COVID [112, 113]. One survey responder from this country does 7000 annual consults. The military is also served.

\section{Volunteer TD}

Teledermatology has been delivered on a charitable basis in developing countries, particularly Africa, where there are few qualified dermatologists. The African Teledermatology Project, coordinated by Stephen Kaddu, based in Graz, Austria, and Carrie Kovarik at the University of Pennsylvania, USA, has established links with Uganda, Botswana, Malawi, Swaziland, Burkina Faso, and Lesotho, giving clinical and educational support to local health workers $[114,115]$.

Based in the UK, the Swinfen Charitable Trust offers teledermatology advice to many countries in Africa, as well 
as in the Middle East and Asia, including Pakistan and Iraq. In 2019, there were 400 Telemedical Links in 84 developing countries, with 692 referring doctors being advised on diagnosis and recommended medical treatment for their patients by some 500 volunteer medical specialists [116].

Médecins Sans Frontières (MSF), a medical humanitarian organization, began using store-and-forward telemedicine in 2010. In 2016, MSF had 271 operational sites in Africa, 74 in the Middle East, 56 in Asia, 37 in Europe, 26 in the Americas, and 4 in the Pacific. By 2017, over 6000 cases have been managed by this telemedicine system. Specialists are volunteers from hospitals or private practice all over the world. Among the medical specialties, dermatology was one of the most frequent subspecialties requested. Experts not available within MSF, such as dermatologists, were based primarily in Europe or the Americas [117].

\section{Conclusions}

Telemedicine increases access to general and specialized health care services, delivers care to rural areas, offers providers greater flexibility in scheduling, and saves patients' time and money in seeking care.

Barriers to telemedicine remain in both developed and developing countries and unnecessarily slow its diffusion. A recent review of global telemedicine barriers cited organizational barriers of cost, reimbursement, liability, privacy, data security, outdated equipment, workflow efficiency, a rural location, and profit, teaching status, and size of organizations. Patient-related barriers were increased age, educational and digital literacy levels, access to enough bandwidth and to a telephone, unawareness of telemedicine, unreasonable expectations of telemedicine, socioeconomic status, unwillingness to be photographed, language barriers, and the perception that telemedicine is impersonal. There are also barriers related to staff and programmers such as technology literacy, resistance to change, poor design, interoperability, and language [118].

When the consult is between the care provider and a specialist, poor uptake of teledermatology may be due to fact that the existence of these services is not widely known to medical practitioners or patients. In addition, a far greater workload and responsibility are placed on the referring doctor [119-121].

When the visit is direct to the patient, barriers to the use of live video include negative attitudes to video; unfamiliarity with video; the perception that the time taken to set up a video consultation will encroach on the time available to attend to the patient; interruption and/or disruption to workflows in the clinic; low competence and/or low confidence with the technology, equipment, and software; and "it's easier to pick up the phone" [122].
When telemedicine adoption came after COVID in Australia, only $3 \%$ of GP telehealth consultations were conducted by video, the rest by telephone, despite the two Australian GP colleges and the National Health Service stating a preference for the use of video rather than phone as a substitute for in-person consultation [123]. Other challenges in implementing outpatient teledermatology in the pandemic are poor image quality, particularly when evaluating pigmented lesions, medico-legal liabilities, and privacy issues during COVID.

The pandemic decreased barriers to TD care in many countries, particularly those with developed technology. Access to care for those with the proper technology tools improved enormously. Coverage for physician services via government or insurance systems was made available in many countries for the first time. Both patients and health care delivery institutions, private and otherwise, rapidly adopted TD to deliver care and became familiar with the possibilities and perils of TD. Reasons for reluctance and acceptance of patients and health care providers to using TD were explored.

By utilizing a survey and personal contacts, we identified that the published literature does not reveal the extent of the ingenuity of applications of teledermatology, particularly in the developing world. Novel mechanisms for knowledge sharing and lessons learned which may be unique to each region would facilitate the growth and utility of teledermatology globally.

Teledermatology growth and application in the future may be possible through the rapid development of AI (augmented or artificial) intelligence, with the potential to alter the way dermatology is practiced. Studies comparing dermatologists to machine-learning computers showed computer algorithms were superior to clinicians in diagnostic accuracy [124, 125]. AI in dermatology might be used in the education of patients and health care trainees, lesion tracking, triage, and treatment response. Teledermatology in combination with AI can allow the use of dermatologist vetted images to be used as a database for machine learning [126].

Although telemedicine shows promise in its ability to increase access and efficiency, ease and acceptance of this modality of care are necessary for its diffusion. Public policy could compensate for barriers common in several countries, but it becomes difficult for many nations to act in accord, particularly when monetary incentives can differ between countries. Future research could start with the assembly of a Delphi team to identify possible common ground for international public policy. From the results of the Delphi team, surveys could go out to an international community inviting standards for interoperability and universal acceptance of telemedicine as a means to expand access to care [127]. 
Abbreviations $A I$, artificial intelligence; COVID-19, coronavirus disease 2019; WHO, World Health Organization; TD, teledermatology; $M S F$, Médecins Sans Frontières

Acknowledgements The contributions of the following colleagues are appreciated by the authors: Isabel Maria del Pilar Casas, MD Argentina; Jose Catacora, MD Peru; Ronnie Cooper MD, Montserrat; Jeffrey Edwards MD, Trinidad and Tobago; Evangeline Handog, MD Philippines; José Hernández, International Teledermatology Society; Dong Huiting, MD, China; Pakinam Nabil Ibrahim, MD Egypt; Mariem Kebe, MD, Mauritania; Gillian Lawrie MD, South Africa; David Moreno-Ramirez, Spain; Jim Muir, MD, Australia; Daniel Holthausen Nunes, MSc, PhD Brazil; Alexey Sergeev, MD, Russia; Lady Patricia Swinfen, Swinfen Charitable Trust, UK; Willie Visser MD, South Africa; and Omid Zargari, MD, Iran and Canada

\section{Declarations}

Conflicts of Interest The authors declare that they have no conflict of interest.

Human and Animal Rights and Informed Consent This article does not contain any studies with human or animal subjects performed by any of the authors.

\section{References}

Papers of particular interest, published recently, have been highlighted as:

- Of importance

-• Of major importance

1. World Health Organization. Telemedicine, opportunities and developments in member states: report on the second global survey on eHealth. 2010. ISBN 978924156414 4. Available from: http:/www.who.int/goe/publications/ehealth_series_vol2/en/ (last accessed 11/28/2020)

2. Atlas of eHealth country profiles: the use of eHealth in support of universal health coverage: based on the findings of the third global survey on eHealth 2015. ISBN 978924156521 9. Available from: https://www.who.int/observatories/global-observatoryforehealth (last accessed 11/28/20)

3. Desai B, McKoy K, Kovarik C. Overview of international teledermatology. Pan Afr Med J. 2010 Jul 20;6:3. (https://oatext. com/pdf/GOD-2-156.pdf. accessed 11/13/20.

4. Gaffney R, Rao B. Global Teledermatology Open Access Text Dec 2015. https://doi.org/10.15761/GOD.1000156)

5. Abbott LM, Magnusson RS, Gibbs E, Smith SD. Smartphone use in dermatology for clinical photography and consultation: Current practice and the law. Australas J Dermatol. 2018 May;59(2):1017. https://doi.org/10.1111/ajd.12583.

6. Glines KR, Haidari W, Ramani L, Akkurt ZM, Feldman SR. Digital future of dermatology. Dermatol Online J. 2020 Oct 15;26(10). 13030/qt75p7q57j.

7. • Yim KM, Florek AG, Oh DH, McKoy K, Armstrong AW. Teledermatology in the United States: An Update in a Dynamic Era. Telemed J E Health, This is the most recent update of teledermatology in the United States. 2018 Sep;24(9):691-7. https://doi.org/10.1089/tmj.2017.0253.
8. Lee JJ, English JC 3rd. Teledermatology: A Review and Update. Am J Clin Dermatol. 2018 Apr;19(2):253-60. https://doi.org/10. 1007/s40257-017-0317-6.

9. Clark AK, Bosanac S, Ho B, Sivamani RK. Systematic review of mobile phone-based teledermatology. Arch Dermatol Res. 2018 Nov;310(9):675-89. https://doi.org/10.1007/s00403-018-1862-4.

10. Zakaria A, Maurer T, Su G, Amerson E. Impact of teledermatology on the accessibility and efficiency of dermatology care in an urban safety-net hospital: A pre-post analysis. J Am Acad Dermatol. 2019 Dec;81(6):1446-52. https://doi.org/10. 1016/j.jaad.2019.08.016.

11. Wang RF, Trinidad J, Lawrence J, Pootrakul L, Forrest LA, Goist $\mathrm{K}$, et al. Improved patient access and outcomes with the integration of an eConsult program (teledermatology) within a large academic medical center. J Am Acad Dermatol. 2019 Oct 31. S0190-9622(19)32976-7.0. https://doi.org/10.1016/j.jaad.2019. 10.053 .

12. Teledermatology Outcomes in the Providence Veterans Health Administration. Telemed J E Health. 2019 Dec;25(12):11831188. https://doi.org/10.1089/tmj.2018.0242.

13. Bianchi MG, Santos A, Cordioli E. Benefits of Teledermatology for Geriatric Patients:Population-Based Cross-Sectional Study. J Med Internet Res. 2020 Apr 21;22(4):e16700. https://doi.org/10. $2196 / 16700$.

14. Dhaduk K, Miller D, Schliftman A, Athar A, Al Aseri ZA, Echevarria A, et al. Implementing and Optimizing Inpatient Access to Dermatology Consultations via Telemedicine: An Experiential Study. Telemed J E Health. 2020 Apr 15. https:// doi.org/10.1089/tmj.2019.0267.

15. Gabel CK, Nguyen E, Karmouta R, Liu KJ, Zhou G, Alloo A, Arakaki R, Balagula Y, Bridges AG, Cowen EW, Davis MDP, Femia A, Harp J, Kaffenberger B, Keller JJ, Kwong BY, Markova A, Mauskar M, Micheletti R, Mostaghimi A, Pierson J, Rosenbach M, Schwager Z, Seminario-Vidal L, Sharon VR, Song PI, Strowd LC, Walls AC, Wanat KA, Wetter DA, Worswick S, Ziemer C, Kvedar J, Mikailov A, Kroshinsky D. Use of teledermatology by dermatology hospitalists is effective in the diagnosis and management of inpatient disease. J Am Acad Dermatol. 2020 May 7: S0190-9622(20)30831-8. https:// doi.org/10.1016/j.jaad.2020.04.171.

16. Coustasse A, Sarkar R, Abodunde B, Metzger BJ, Slater CM. Use of Teledermatology to Improve Dermatological Access in Rural Areas. Telemed J E Health. 2019 Nov;25(11):1022-32. https:// doi.org/10.1089/tmj.2018.0130.

17. Kornmehl H, Singh S, Johnson MA, Armstrong AW. DirectAccess Online Care for the Management of Atopic Dermatitis: A Randomized Clinical Trial Examining Patient Quality of Life. Telemed J E Health. 2017 Sep;23(9):726-32. https://doi.org/10. 1089/tmj.2016.0249.

18. Khosravi H, Zhang S, Siripong N, Moorhead A, English Iii JC. Comparing acne followup:teledermatology versus outpatient dermatology visits. Dermatol Online J. 2020 Apr 15;26(4):13030/ qt1424r02m.

19. Bianciardi Valassina MF, Bella S, Murgia F, Carestia A, Prosseda E. Telemedicine in pediatric wound care. Clin Ter. 2016;167(1): e21-3. https://doi.org/10.7417/T.2016.1915.

20. Dahy A, El-Qushayri AE, Mahmoud AR, Al-Kelany TA, Salman $\mathrm{S}$. Telemedicine approach for psoriasis management, time for application? A systematic review of published studies. Dermatol Ther. 2020 Jun;27:e13908. https://doi.org/10.1111/dth.13908.

21. Brunasso AMG, Massone C. Teledermatologic monitoring for chronic cutaneous autoimmune diseases with smartworking during COVID-19 emergency in a tertiary center in Italy. Dermatol Ther. 2020 Jul;33(4):e13495. https://doi.org/10.1111/dth.13695.

22. Perkins S, Cohen JM, Nelson CA, Bunick CG. Teledermatology in the era of COVID-19: Experience of an academic department of 
dermatology. J Am Acad Dermatol. 2020 Jul;83(1):e43-4. https:// doi.org/10.1016/j.jaad.2020.04.048.

23. Marchell R, Locatis C, Burgess G, Maisiak R, Liu WL, Ackerman M. Patient and Provider Satisfaction with Teledermatology. Telemed J E Health. 2017 Aug;23(8):684-90. https://doi.org/10. 1089/tmj.2016.0192.

24. Whitten P, Love B. Patient and provider satisfaction with the use of telemedicine: Overview and rationale for cautious enthusiasm. J Postgrad Med. 2005;51:294-300.

25. Baranowski MLH, Balakrishnan V, Chen SC. Patient Satisfaction with the Veteran's Administration Teledermatology Service. J Am Acad Dermatol. 2019 Jan;28:S0190-9622(19)30143-4. https:// doi.org/10.1016/j.jaad.2019.01.036.

26. Hadeler E, Gitlow H, Nouri K. Definitions, survey methods, and findings of patient satisfaction studies in teledermatology: a systematic review. Arch Dermatol Res. 2020 Jul;28:1-11. https://doi. org/10.1007/s00403-020-02110-0.

27. Goldstein Market Intelligence. Teledermatology Market Outlook 2030: Market Segmentation By Mode Of Services, By Service Providers, By End Users \& By Region With Forecast 2017 2030. (2020. September 1).https://www.goldsteinresearch.com/ report/tele-dermatology-market-outlook-2024-globalopportunity-and-demand-analysis-market-forecast-2016-2024. last accessed November 12,2020

28.• “ Bhargava S, McKeever C, Kroumpouzos G. Impact of covid-19 pandemic on dermatology practice: results of a web-based, global survey. Int J Womens Dermatol. 2020 Oct 12. https://doi.org/10. 1016/j.ijwd.2020.09.010 This global survey of over 700 dermatologists discusses the effect of the COVID 19 Pandemic on dermatology practice and the use of teledermatology.

29. Mariano Suppa. Impact of Covid 19 pandemic on dermatologists life and practice. (2020. October 31) European Association of Dermatology and Venereology meeting. https://www.mdedge. com/dermatology/article/231089/coronavirus-updates/surveyfindseuropean-dermatologists-unhappy-pandemic (accessed November 25, 2020).

30. Gupta R, Ibraheim MK, Doan HQ. Teledermatology in the wake of COVID-19:Advantages and challenges to continued care in a time of disarray. J Am Acad Dermatol. 2020 Jul;83(1):168-9. https://doi.org/10.1016/j.jaad.2020.04.080.

31. Kazi R, Evankovich MR, Liu R, Liu A, Moorhead A, Ferris LK, et al. Utilization of Asynchronous and Synchronous Teledermatology in a Large Health Care System During the COVID-19 Pandemic. Telemed J E Health. 2020 Oct 19. https:// doi.org/10.1089/tmj.2020.0299.

32. Price KN, Thiede R, Shi VY, Curiel-Lewandrowski C. Strategic dermatology clinical operations during COVID-19 pandemic. J Am Acad Dermatol. 2020;82(6):e207-9.

33. Soutou B, Tomb R. The Multifaceted Engagement of the Dermatologist in the Covid- 19 Pandemic. SN Compr Clin Med. $2020 \mathrm{Jul} ; 22: 1-5$. https://doi.org/10.1007/s42399-020-00423-9.

34. Rismiller K, Cartron AM, Trinidad JCL. Inpatient teledermatology during the COVID-19 pandemic. J Dermatolog Treat. 2020 Aug;31(5):441-3. https://doi.org/10.1080/09546634. 2020.1762843

35. Bhat YJ, Aslam A, Hassan I, Dogra S. Impact of COVID-19 Pandemic on Dermatologists and Dermatology Practice. Indian Dermatol Online J. 2020 May 10;11(3):328-32. https://doi.org/ 10.4103/idoj.IDOJ 18020.

36. Altunisik N, Turkmen D, Calikoglu E, Sener S. Views and Experiences of Dermatologists in Turkey Regarding Teledermatology during the COVID-19 Pandemic. J Cosmet Dermatol. 2020 Aug 16. https://doi.org/10.1111/jocd.13677.

37. Kumar S, Bishnoi A, Vinay K. Changing paradigms of dermatology practice in developing nations in the shadow of COVID-19:
Lessons learnt from the pandemic. Dermatol Ther. 2020 Jul;33(4): e13472. https://doi.org/10.1111/dth.13472.

38. Public Health Front. (2020 October 16) Telemedicine Across the Globe-Position Paper From the COVID-19 Pandemic Health System Resilience PROGRAM (REPROGRAM) International Consortium (Part 1)/. https://www.frontiersin.org/articles/10. 3389/fpubh.2020.556720/endnote (accessed November 29, 2020)

39. Lee JJ, English JC 3rd. Teledermatology: A Review and Update. Am J Clin Dermatol. 2018 Apr;19(2):253-60. https://doi.org/10. 1007/s40257-017-0317-6.

40. Provincial Telehealth Resources: An Interactive Map of Canada. (2020). Available online at: https://www.bbd.ca/blog/telehealthresources-canada/ (accessed on September 11, 2020)

41. Canad's Health Informatics Association. 2015 Canadian Telehealth Report. https://ivecare.ca/sites/default/files/2015\% 20TeleHealth-Public-eBook-Final-10-9-15-secured.pdf (accessed November 23,2020)

42. Barclay, Shane. British Columbia Medical Association. ConsultDerm BC Physician How-to Guide. https://sharedcarebc. $\mathrm{ca} /$ sites/default/files/ConsultDermBC_How to_Use_FINAL.pdf. (accessed November 11,2020).

43. OTN, Government of Ontario. 2020 Teledermatology. https://otn. ca/providers/telederm/ (accessed November 23, 2020)

44. Canadian Medical Association. 2019 CMA Physician Workforce Survey results. https://www.cma.ca/2019-cma-physicianworkforce-survey-results. https://surveys.cma.ca/en/viewer? file $=\% 2$ fdocuments $\% 2$ fSurveyPDF\%2fCMA_Survey Workforce2019_Q17_Electronic\%20Tools-e.pdf\#phrase=false. (accessed April 27,2021)

45. CMAG News. Canadian Medical Association. 2020. February 12. (https://cmajnews.com/2020/02/12/virtual-care-1095851/) (accessed November 23, 2020)

46. Guadeloupe Estrada, International Society of Dermatology 8th World Congress presentation Oct 26, 2020

47. Atlas of eHealth country profiles: the use of eHealth in support of universal health coverage: based on the findings of the third global survey on eHealth 2015. ISBN 9789241565219 Available from: https://www.who.int/observatories/global-observatory-forehealth (accessed 11/28/20)

48. - Cordioli, Eduardo. Developing a Large-scale Tele-dermatology Program. presentation 2019 HIMMS conference, https://365. himss.org/sites/himss365/files/365/handouts/552578778/ handout-268.pdf. (accessed November 28, 2020). Discussion of developing the largest teledermatology program in South America.

49. Assis TG, Palhares DM, Alkmim MB, Marcolino MS. Teledermatology for primary care in remote areas in Brazil. J Telemed Telecare. 2013 Dec;19(8):494-5. https://doi.org/10. 1177/1357633X13512059.

50. Giavina Bianchi M, Santos A, Cordioli E. Dermatologists' perceptions on the utility and limitations of teledermatology after examining 55,000 lesions. J Telemed Telecare. 2019 Aug 14: 1357633 X19864829. https://doi.org/10.1177/ $1357633 X 19864829$.

51. Giavina Bianchi M, Santos AP, Cordioli E. The majority of skin lesions in pediatric primary care attention could be managed by Teledermatology. PLoS One. 2019 Dec 2;14(12):e0225479. https://doi.org/10.1371/journal.pone.0225479.

52. Teledermatology for primary care in remote areas in Brazil. Available from:https://www.researchgate.net/publication/ 258336045 Teledermatology for primary care in remote areas_in_Brazil [accessed Nov 23, 2020].

53. An Analysis of Telemedicine Experiences and Services in Chile By Antonio Rienzo Renato January 21st 2019. https://doi.org/10. 5772/intechopen.81756. https://www.intechopen.com/books/ 
telehealth/an-analysis-oftelemedicine-experiences-and-servicesin-chile. (Accessed 11/20/2020)

54. Messagier AL, Blaizot R, Couppié P, Delaigue S. Teledermatology Use in Remote Areas of French Guiana: Experience from a Long-Running System. Front Public Health. 2019 Dec 19;7:387. https://doi.org/10.3389/fpubh.2019.00387.

55. BN Americas. Is COVID-19 the Push e-Health Needed? (2020). Available online at: https://www.bnamericas.com/en/features/iscovid-19-the-push-e-health-needed (accessed on November 23, 2020).

56. Romero G, de Argila D, Ferrandiz L, Sánchez MP, Vañó S, Taberner R, et al. Practice Models in Teledermatology in Spain: Longitudinal Study, 2009-2014. Actas Dermosifiliogr. 2018 Sep;109(7):624-30. https://doi.org/10.1016/j.ad.2018.03.015.

57. van der Heijden J. Teledermatology integrated in the Dutch national healthcare system. J Eur Acad Dermatol Venereol. 2010 May;24(5):615-6; author reply 616-9. https://doi.org/10.1111/j. 1468-3083.2010.03595.x.

58. Mehrtens SH, Shall L, Halpern SM. A 14-year review of a UK teledermatology service: experience of over 40000 teleconsultations. Clin Exp Dermatol. 2019 Dec;44(8):874-81. https://doi.org/10.1111/ced.13928.

59. Mehrtens SH, Halpern SM. Changing use and attitudes towards teledermatology in the U.K. over 10 years: results of the 2016 National Survey. Br J Dermatol. 2018 Jan;178(1):286-8. https:// doi.org/10.1111/bjd.15606.

60. van der Heijden JP, de Keizer NF, Bos JD, Spuls PI, Witkamp L. Teledermatology applied following patient selection by general practitioners in daily practice improves efficiency and quality of care at lower cost. Br J Dermatol. 2011 Nov;165(5):1058-65. https://doi.org/10.1111/j.1365-2133.2011.10509.x.

61. Eber EL, Janda M, Arzberger E, Hofmann-Wellenhof R. Survey on the status of teledermatology in Austria. J Dtsch Dermatol Ges. 2019 Jan;17(1):25-31. https://doi.org/10.1111/ddg.13729.

62. Kips J, Lambert J, Ongenae K, De Sutter A, Verhaeghe E. Teledermatology in Belgium: a pilot study. Acta Clin Belg. 2020 Apr;75(2):116-22. https://doi.org/10.1080/17843286.2018. 1561812

63. Maltagliati-Holzner P. Teledermatologie in der Schweiz : Anwendungsbeispiele zur Behandlung von dermatologischen Fragestellungen anhand eines telemedizinischen Zentrums [Teledermatology in Switzerland : Set-up for and examples of dermatological treatment from a telemedicine center]. Hautarzt. 2019 May;70(5):329-34. German. https://doi.org/10.1007/ s00105-019-4401-0.

64. Bertin C, Diakite A, Carton B, Wozniak C, Nathanson S, Monnier $\mathrm{S}$, et al. Télédermatologie unissant deux hôpitaux : deux ans d'expérience [Teledermatology between two French hospitals: Two years of experience]. Ann Dermatol Venereol. 2017 Dec;144(12):759-67. French. https://doi.org/10.1016/j.annder. 2017.06.011.

65. Nathanson S, Dommergues MA, Hentgen V, Arditty F, Greder Belan A, Carton B, et al. Apport de la télédermatologie dans un service de pédiatrie hospitalière [Contribution of teledermatology in a hospital pediatrics department]. Arch Pediatr. 2018 Jan;25(1): 13-7. French. https://doi.org/10.1016/j.arcped.2017.10.027.

66. Kjærsgaard Andersen R, Jemec GBE. Teledermatology management of difficult-totreat dermatoses in the Faroe Islands. Acta Dermatovenerol Alp Pannonica Adriat. 2019 Sep;28(3):103-5.

67. Khatibi B, Bambe A, Chantalat C, Resche-Rigon M, Sanna A, Fac $\mathrm{C}$, et al. Télédermatologie en milieu carcéral : étude rétrospective de 500 télé-expertises [Teledermatology in a prison setting: A retrospective study of 500 expert opinions]. Ann Dermatol Venereol. 2016 Jun-Jul;143(6-7):418-22. French. https://doi.org/ 10.1016/j.annder.2015.12.018.

68. Jünger M, Arnold A, Lutze S. Teledermatologie zur notfallmedizinischen Patientenversorgung : Zweijahreserfahrungen mit teledermatologischer Notfallversorgung [Teledermatology for emergency patient care : Two-year experience with teledermatological emergency care]. Hautarzt. 2019 May;70(5):324-8. German. https://doi.org/10. 1007/s00105-019-4384-x.

69. Cazzaniga S, Castelli E, Di Landro A, Di Mercurio M, Imberti G, Locatelli GA, et al. Mobile teledermatology for melanoma detection: Assessment of the validity in the framework of a populationbased skin cancer awareness campaign in northern Italy. J Am Acad Dermatol. 2019 Jul;81(1):257-60. https://doi.org/10.1016/ j.jaad.2019.02.036.

70. Rizvi SMH, Schopf T, Sangha A, Ulvin K, Gjersvik P. Teledermatology in Norway using a mobile phone app. PLoS One. 2020 Apr 27;15(4):e0232131. https://doi.org/10.1371/ journal.pone.0232131.

71. Koller S, Hofmann-Wellenhof R, Hayn D, Weger W, Kastner P, Schreier G, et al. Teledermatological monitoring of psoriasis patients on biologic therapy. Acta Derm Venereol. 2011 Oct;91(6): 680-5. https://doi.org/10.2340/00015555-1148.

72. Kravets K, Vasylenko O, Dranyk Z, Bogomolets O. Store-andforward teledermatology for the most common skin neoplasms in Ukraine. Acta Dermatovenerol Alp Pannonica Adriat. 2018 Jun;27(2):79-83.

73. Atlas of eHealth country profiles: the use of eHealth in support of universal health coverage: based on the findings of the third global survey on eHealth 2015. ISBN 9789241565219 Available from: https://www.who.int/observatories/global-observatory-forehealth (accessed November 28,2020)

74. Altunisik N, Turkmen D, Calikoglu E, Sener S. Views and Experiences of Dermatologists in Turkey Regarding Teledermatology during the COVID-19 Pandemic [published online ahead of print, 2020 Aug 16]. J Cosmet Dermatol. 2020. https://doi.org/10.1111/jocd.13677.

75. Saleh N, Abdel Hay R, Hegazy R, et al. Can teledermatology be a useful diagnostic tool in dermatology practice in remote areas? An Egyptian experience with 600 patients. J Telemed Telecare. 2017;23:233-8.

76. International Finance Corporation. https://www.ifc.org/wps/wcm/ connect/news_ext_content/ifc_external_corporate_site/news+ and+events/news/cm-stories/cm-connecting-africa\#page 9 . Accessed Feb 4, 2021.

77. raining in Africa: Successes and Challenges. Dermatol Clin. 2021 Jan;39(1):57-71. https://doi.org/10.1016/j.det.2020.08.006.

78. Fondation Pierre Fabre. https://www.fondationpierrefabre.org/en/ teledermatology-implemented-in-mauritania/. Accessed Feb 6, 2021

79. Walters LE, Mars M, Scott RE. A Review and Critique of Teledermatology in the South African Public Health Sector. Stud Health Technol Inform. 2016;231:143-51.

80.• “ Bhaskar S, Bradley S, Chattu VK, et al. Telemedicine Across the Globe-Position Paper From the COVID-19 Pandemic Health System Resilience PROGRAM (REPROGRAM) International Consortium (Part 1). Front Public Health. 2020;8:556720. Published 2020 Oct 16. https://doi.org/10.3389/fpubh.2020. 556720 Examines telemedicine frameworks across countries, the status or maturity of telemedicine implementation, and the changes that have been adopted during the COVID-19 
pandemic. A comparative analysis was done of existing telemedicine frameworks and recommendations made by this consortium on improving telemedicine uptake during and beyond COVID-19.

81. Hamilton C. Telemedicine in Kazakhstan: Bridging the UrbanRural Divide in Delivering Prevention, Diagnosis, and Treatment of Noncommunicable Diseases. World Health Organization Regional Office for Europe: Division of Health Systems and Public Health; 2018.

82. Atlas of eHealth country profiles: the use of eHealth in support of universal health coverage: based on the findings of the third global survey on eHealth 2015. ISBN 978924156521 9. Available from: https://www.who.int/observatories/global-observatoryforehealth (last accessed 11/28/20

83. Bhaskar S, Bradley S, Chattu VK, et al. Telemedicine Across the Globe-Position Paper From the COVID-19 Pandemic Health System Resilience PROGRAM (REPROGRAM) International Consortium (Part 1). Front Public Health. 2020;8:556720. Published 2020 Oct 16. https://doi.org/10.3389/fpubh.2020. 556720.

84. Ashique KT, Kaliyadan F. Teledermatology in the Wake of COVID -19 Scenario: An Indian Perspective. Indian Dermatol Online J. 2020 May 10;11(3):301-6. https://doi.org/10.4103/ idoj.IDOJ_260_20.

85. Atlas of eHealth country profiles: the use of eHealth in support of universal health coverage: based on the findings of the third global survey on eHealth 2015. ISBN 9789241565219 Available from: https://www.who.int/observatories/global-observatory-forehealth. (accessed 11/28/20)

86. Bhaskar S, Bradley S, Chattu VK, et al. Telemedicine Across the Globe-Position Paper From the COVID-19 Pandemic Health System Resilience PROGRAM (REPROGRAM) International Consortium (Part 1). Front Public Health. 2020; 8:556720. Published 2020 Oct 16. https://doi.org/10.3389/fpubh.2020. 556720. https://www.frontiersin.org/articles/10.3389/fpubh.2020. 556720/full\#B52. (accessed November 28,2020)

87. Atlas of eHealth country profiles: the use of eHealth in support of universal health coverage: based on the findings of the third global survey on eHealth 2015. ISBN 9789241565219 . Available from: https://www.who.int/observatories/global-observatoryforehealth. (accessed November 28,2020)

88. Bhaskar S, Bradley S, Chattu VK, et al. Telemedicine Across the Globe-Position Paper From the COVID-19 Pandemic Health System Resilience PROGRAM (REPROGRAM) International Consortium (Part 1). Front Public Health. 2020; 8:556720. Published 2020 Oct 16. https://doi.org/10.3389/fpubh.2020. 556720. https://www.frontiersin.org/articles/10.3389/fpubh.2020. 556720/full\#B52 (accessed November 25, 2020)

89. Atlas of eHealth country profiles: the use of eHealth in support of universal health coverage: based on the findings of the third global survey on eHealth 2015. ISBN 9789241565219 . Available from: https://www.who.int/observatories/global-observatoryforehealth. (accessed November 28,2020)

90. Bhaskar S, Bradley S, Chattu VK, et al. Telemedicine Across the Globe-Position Paper From the COVID-19 Pandemic Health System Resilience PROGRAM (REPROGRAM) International Consortium (Part 1). Front Public Health. 2020;8:556720. Published 2020 Oct 16. https://doi.org/10.3389/fpubh.2020. 556720

91. Yong Cui, Telemedicine and AI for dermatology care in China, presentation 8th World Congress, International Society of Teledermatology, 5-6 November,2020.
92. Li CX, Shen CB, Xue K, Shen X, Jing Y, Wang ZY, et al. Artificial intelligence in dermatology: past, present, and future. Chin Med J. 2019;00:00-0. https://doi.org/10.1097/CM9. 0000000000000372 .

93. Wu H, Yin $\mathrm{H}$, Chen $\mathrm{H}$, Sun M, Liu X, Yu Y, et al. A deep learning, image-based approach for automated diagnosis for inflammatory skin diseases. Ann Transl Med. 2020;8(9):581. https://doi.org/10.21037/atm.2020.04.39.

94. Shen C, Li C, Xu F, et al. Web-based study on Chinese dermatologists' attitudes towards artificial intelligence. Ann Transl Med. 2020;8(11)):698. https://doi.org/10.21037/atm.2019.12.102.

95. Lee CH, Huang CC, Huang JT, Wang CC, Fan S, Wang PS, et al. Live-interactive teledermatology program in Taiwan: One-year experience serving a district hospital in rural Taitung County. J Formos Med Assoc. 2020 Jun 17:S0929-6646(20)30236-9. https://doi.org/10.1016/j.jfma.2020.06.007.

96. Byamba K, Syed-Abdul S, García-Romero M, et al. Mobile teledermatology for a prompter and more efficient dermatological care in rural Mongolia. Br J Dermatol. 2015;173(1):265-7. https:// doi.org/10.1111/bjd.13607.

97. Seol JE, Park SH, Kim H. Analysis of live interactive teledermatologic consultations for prisoners in Korea for 3 years. J Telemed Telecare. 2018 Oct;24(9):623-8. https://doi.org/10. $1177 / 1357633 X 17732095$.

98. Shin H, Kim DH, Ryu HH, Yoon SY, Jo SJ. Teledermatology consultation using a smartphone multimedia messaging service for common skin diseases in the Korean army: clinical evaluation of its diagnostic accuracy. J Telemed Telecare. 2014;20:70-4.

99. Atlas of eHealth country profiles: the use of eHealth in support of universal health coverage: based on the findings of the third global survey on eHealth 2015. ISBN 9789241565219 . Available from: https://www.who.int/observatories/global-observatoryforehealth (accessed November 28,2020)

100. Lam JA, Dang LT, Phan NT, Trinh HT, Vu NC, Nguyen CK. Mobile Health Initiatives in Vietnam: Scoping Study. JMIR Mhealth Uhealth. 2018;6(4):e106. Published 2018 Apr 24. https://doi.org/10.2196/mhealth.8639.

101. Robinson, Sudanthy "Clinical Updates in COVID-19 https:// twitter.com/clinUp_covid" https://docs.google.com/presentation/ d/1JS9X_xQLN3mIzmmgLvarbdH1RNYK3hlgjNUVP8bvPo0/ edit\#slide=id.p2. (accessed December 3,2020)

102. Atlas of eHealth country profiles: the use of eHealth in support of universal health coverage: based on the findings of the third global survey on eHealth 2015. ISBN 9789241565219 Available from: https://www.who.int/observatories/global-observatory-forehealth. (accessed November 28,2020)

103. Philippine Dermatological Society https://pds.org.ph/pdsinstitutions-providing-freeteledermatology-service/ (accessed December 2, 2020)

104. Philippine Dermatological Society https://pds.org.ph/pds_new/ wpcontent/uploads/2020/05/1.TELEDERMATOLOGY.pdf (accessed December 2, 2020)

105. Abbott LM, Miller R, Janda M, Bennett H, Taylor M, Arnold C, et al. Practice guidelines for teledermatology inAustralia. Australas J Dermatol. 2020;61:e293-302. https://doi.org/10.1111/ajd.13301.

106. Colgrave, Nevin. Teledermatology - a proposed model for the Australian Defence Force [online]. Journal of Military and Veterans Health, Vol. 24, No. 4, Oct 2016: 75-81. Availability: $<$ https://search.informit.com.au/documentSummary;dn= 599626092285731;res=IELHEA > ISSN: 1835-1271. [cited 03 Dec 20]. 
107. Byrom L, Lucas L, Sheedy V, Madison K, McIver L, Castrisos G, et al. Tele-Derm National: A decade of teledermatology in rural and remote Australia. Aust J Rural Health. 2016 Jun;24(3):193-9. https://doi.org/10.1111/ajr.12248.

108. Abbott LM, Magnusson RS, Gibbs E, Smith SD. Smartphone use in dermatology for clinical photography and consultation: current practice and the law. Australas J Dermatol. 2018;59(2):101-7.

109. Atlas of eHealth country profiles: the use of eHealth in support of universal health coverage: based on the findings of the third global survey on eHealth 2015. ISBN 978924156521 9. Available from: https://www.who.int/observatories/global-observatoryforehealth. (accessed November 28, 2020)

110. Skin cancer referrals in New Zealand: Teledermatology expediting treatment Julia Gao, Amanda Oakley. Presented at George Washington University presented at Research Days 2019. Poster, 5-1-2019 https://hsrc.himmelfarb.gwu.edu/gw_research_days/ 2019/SMHS/9/. (accessed December 2, 2020)

111. DermNetNZ. https://dermnetnz.org/topics/teledermatology/ (accessed December 2, 2020)

112. McDonald, Kate. 2020 April 21. COVID-19 resources: specialties and allied health https://www.pulseitmagazine.com.au/news/ australian-ehealth/5457-covid-19-resourcesspecialties-and-alliedhealth, (accessed December 2,2020)

113. Teledermatology during COVID 19. New Zealand Dermatological Society. 3 April,2020 https://www.nzdsi.org/ View.aspx?articleid=df258441-65a5-4d00-bae8-90b2c814d6d1 (accessed December 2,2020)

114. Weinberg J, Kaddu S, Gabler G, Kovarik C. The African Teledermatology Project:Providing access to dermatologic care and education in sub-Saharan Africa. Pan Afr Med J. 2009;3:16 Published 2009 Nov 19.

115. Lipoff JB, Cobos G, Kaddu S, Kovarik CL. The Africa Teledermatology Project: A retrospective case review of 1229 consultations from sub-Saharan Africa. J Am Acad Dermatol. 2015 Jun;72(6):1084-5. https://doi.org/10.1016/j.jaad.2015.02. 1119.

18. Trustees Report 2019. Swinfen Charitable Trust. https://www. swinfencharitabletrust.org/website-content/annual-report-20191604570882.pdf. (Accessed December 3,2020)

117. Delaigue S, Bonnardot L, Steichen O, et al. Seven years of telemedicine in Médecins Sans Frontières demonstrate that offering direct specialist expertise in the frontline brings clinical and educational value. J Glob Health. 2018;8(2):020414. https://doi.org/ 10.7189/jogh.08.02041.
118. Scott Kruse C, Karem P, Shifflett K, Vegi L, Ravi K, Brooks M. Evaluating barriers to adopting telemedicine worldwide: A systematic review. J Telemed Telecare. 2018;24(1):4-12. https:// doi.org/10.1177/1357633X1667408s.

119. The Royal Australian College of General Practitioners. Telehealth: the specialist perspective. https://www.racgp.org.au/ afp/2014/december/telehealth-the-specialistperspective/. (Accessed December 2, 2020)

120. Lim TLC. Challenges of teledermatology in rural Australia. Our Dermatol Online. 2020;11(4):409-11.

121. McPhee E. Telehealth: the general practice perspective. Aust Fam Physician. 2014 Dec;43(12):826-7.

122. Baird, Andrew. 2020 September 1. Pulse+It. https://www. pulseitmagazine.com.au/news/australian-ehealth/5687-why-areaustraliangps-doing-relatively-few-video-consultations (accessed December 15, 2020)

123. Baird, Andrew. 2020 September 1. Pulse+It. https://www. pulseitmagazine.com.au/news/australian-ehealth/5687-why-areaustraliangps-doing-relatively-few-video-consultations (accessed December 15, 2020)

124. Esteva A, Kuprel B, Novoa RA, Ko J, Swetter SM, Blau HM, et al. Dermatologist level classification of skin cancer with deep neural networks. Nature. 2017 Feb 2;542(7639):115-8. https:// doi.org/10.1038/nature21056 Epub 2017 Jan 25. Erratum in: Nature. 2017 Jun 28;546(7660):686.

125. Tschandl P, Codella N, Akay BN, Argenziano G, Braun RP, Cabo $\mathrm{H}$, et al. Comparison of the accuracy of human readers versus machine-learning algorithms for pigmented skin lesion classification: an open, web-based, international, diagnostic study. Lancet Oncol. 2019 Jul;20(7):938-47. https://doi.org/10.1016/S14702045(19)30333-X.

126. Sharma P, Vleugels RA, Nambudiri VE. Augmented reality in dermatology: Are we ready for AR? J Am Acad Dermatol. 2019 Nov;81(5):1216-22. https://doi.org/10.1016/j.jaad.2019.07.008.

127. Scott Kruse C, Karem P, Shifflett K, Vegi L, Ravi K, Brooks M. Evaluating barriers to adopting telemedicine worldwide: A systematic review. J Telemed Telecare. 2018;24(1):4-12. https:// doi.org/10.1177/1357633X1667408s.

Publisher's Note Springer Nature remains neutral with regard to jurisdictional claims in published maps and institutional affiliations. 